\title{
Local Government Behavior and Property Right Formation in Rural China
}

\author{
Loren Brandt, Scott Rozelle, and, Matthew A. Turner
}

Abstract: Secure land tenure is important to the development process, but China's rural reforms have so far failed to provide farm households with this security. We examine the political economy of land tenure and find that local governments sacrifice tenure security in the interests of efficiency and equity. Local rent seeking also plays an important role, and is a likely source of the under-development of land rental markets. Our results further suggest that decreases in distortionary taxes and increases in the integrity of elections will lead to more secure tenure and an increased reliance on market land exchange. (JEL: R52, Q13.)

\section{Introduction}

A cornerstone of the transition from a centrally planned to a market economy is the establishment of a well-defined system of property rights. China's agricultural sector began this transition in the early 1980's when the Household Responsibility System (HRS) dismantled China's collectives and granted households use rights to the land in return for meeting tax and quota obligations. The reforms, however, have not produced the right to secure tenure. Two decades after the implementation of HRS, land tenure remains insecure in a majority of villages and land rental markets are thin, if they operate at all. The cause of the insecurity is clear: Local governments routinely confiscate land from some households in the village and redistribute it to others. The reason land rental markets have not evolved is less obvious.

In order to understand the determinants of tenure security in rural China, we analyze land reallocation behavior of local governments using data collected for this purpose. The importance of this analysis for Chinese agricultural policy is clear. Since local governments commonly influence property rights in developing and transition economies (e.g. BOYCKO, SHLIEFER, and VisHNy [1995], Alston, LibeCAP, AND BERNARDO [1997], LIBECAP [1979]), our analysis offers insight into an issue fundamental to an understanding of these economies: The political economy of property rights formation.

We find that local governments reallocate land for a variety of reasons. Much of this reallocation behavior can be explained by an efficiency hypothesis. In the context of a rural economy where land rental markets and on-farm labor markets are largely missing, local governments use reallocations to move land from lower to higher valued uses, and to help reduce the excess burden of land taxes. The costs associated with these allocations, in turn, influence both their size and frequency. ${ }^{1}$ We also find a link between land reallocation

\footnotetext{
${ }^{1}$ These costs include the transactions costs associated with the reallocation itself, and dynamic incentive costs related to the effect of tenure insecurity on investment. For reasons explained below, in the paper we focus primarily on the former.
} 
behavior and concerns for equity. In some cases, local governments use reallocations to equalize household access to land. The equity motive, however, appears to be much less important empirically than efficiency. Finally, despite the role we ascribe to efficiency considerations, we find preliminary evidence that rent-seeking behavior by local leaders underlies both the failure of land markets to develop and, the persistence of administrative reallocation in an increasingly marketized economy.

Our results have important policy implications. Lower taxes on land or measures that reduce the effort required by local leaders to enforce the collection of land taxes will help foster more secure land tenure and encourage the emergence of land rental markets. Our results also suggest that reforms which increase the ability of villagers to remove narrowly self-interested leaders from office improve land rights and rental markets. Since administrative reallocations leave significant gains from trade unexploited [BENJAMIN AND BRANDT, 2002], measures that reduce the need for land allocations, increase tenure security and allow land rental markets to transfer land among individuals, likely will produce important welfare gains.

\section{Institutional Background}

Twenty years of economic reform in rural China have produced a system in which farming is jointly conducted by farmers and local leaders [PUTTERMAN, 1993]. In the late 1970s and early 1980s, the Household Responsibility System dismantled agricultural collectives and allocated farmland to households. After paying local taxes and meeting a mandatory delivery quota (which typically involves selling a fixed amount of grain or cash crop at a below-market price to the state procurement system), households were entitled to the rest of the income that they produced on their land. Reformers did not privatize land however, but instead gave ownership rights to the collective (or, as we henceforth call it, the village). Using their authority over land, one of a local leader's principal responsibilities was to allocate cultivated land to households. Although most farmers have well-defined income and control rights, in some villages a leader retains control over crop choice and the decision to rent land to other households [ROZELLE, 1994].

In most villages, village land management is conducted by one or more members of the village executive committee. The main actors in this executive committee are typically the party secretary and the village head. The party secretary is selected by higher-level party organizations. ${ }^{2}$ The village head, on the other hand, may be appointed by township government officials, elected by villagers in a formal election process, or selected by a village representative assembly [O’BRIEN AND LI, 1999; PASTOR AND TAN, 2000]. Although the division of administrative responsibility between the party secretary and the village head is not always well-defined, higher levels of government evaluate them both on the basis of their success in meeting targets set by higher levels of government for family planning, quota fulfillment, tax collection and maintaining farm output [WHITING, 1996]. Performance contracts tie their wages and promotion explicitly to meeting these targets

\footnotetext{
${ }^{2}$ In China, the lowest three levels of the government hierarchy in descending order are the county, township and village. A county consists of approximately 10 to 15 townships. A township consists of 10 to 15 villages. During our study period, township party officials typically appointed village party secretaries. Occasionally, however, county party officials appointed them.
} 
and to other economic and social variables like village economic growth and equity [Ho, 1994; ROZELLE, 1994; O’BRIEN AND LI, 1999].

Local leaders also are accountable to villagers [O’BRIEN AND LI, 1999]. Leaders are subject to direct lobbying by the villagers. Villagers also indirectly influence local leader decisions by lobbying township leaders, who in turn, can pressure local leaders. Finally election laws in some communities affect the decisions of local leaders who increasingly must stand for competitive elections.

Although local leaders have considerable discretion, upper-level government officials often try to dictate policy, in particular the manner in which cultivated land is to be managed. ${ }^{3}$ For example, in the initial State Council documents codifying HRS, the collective was supposed to allocate land to farmers for 15 years. In 1999, a new land law set a new contracting period for 30 years. Almost everyone in China's government knows these rules, from those in the Ministry of Agriculture to the local leaders of China's most remote villages. These policies, however, have not been followed.

\section{Table 1 about here}

Tenure security is largely determined by the frequency and magnitude of village-wide land reallocations. In these reallocations, all or part of the land is taken back from households and re-divided among existing and new households in the village. According to our data, in more than two-thirds of villages, local leaders have reallocated land among households at least once (Table 1). ${ }^{4}$ Conditional on reallocation, the average number of administrative reallocations between 1982 and 1995 is 2.3. Data on the percentage of land that local leaders have reallocated since the advent of the reforms demonstrate that slightly more than half of all farmland has changed hands at least once. On the other hand, based on data for the most recent reallocations in these villages, we find that a typical reallocation involves two-thirds of a village's land and three-quarters of its households.

Land in rural China can also move among households in rental transactions. Although 70 percent of surveyed villages report that households enjoy unencumbered rights to rent land in 1995, the land rental market is thin (Table 2). Despite doubling since 1988, in 1995 China's farmers still rented out less than three percent of the land that they cultivated. The market for agricultural labor is equally thin. Only half of all villages report the use of hired farm labor in 1995, up from one quarter in 1988. Our estimates suggest that farmers in China hire less than one percent of their agricultural labor. ${ }^{5}$

\section{Table 2 about here}

While the markets for land rental and farm labor are poorly developed, the market for non-farm labor has boomed. Our data show that employment in local village and

\footnotetext{
${ }^{3}$ There is currently considerable debate about how much latitude local officials should have over land. Current regulations prohibit larger reallocations and only allow leaders to make small adjustments to benefit the community.

${ }^{4}$ These data are discussed more fully in Section 4 .

${ }^{5}$ In 1988, the number of individuals hired per village was less than 10, and in 1995 only 25 . Household level data suggest that individuals worked on average 75 days per year in farming, implying that only about one-half of one percent of farm labor was hired in 1995.
} 
township-run enterprises, family businesses, and long-term employment outside the village doubled between 1988 and 1995, even though the labor force grew only modestly. By 1995, between 35 and 40 percent of the local labor force was employed outside of agriculture either full or part time, a level consistent with that reported at the national level [STATISTICAL YEARBOOK OF CHINA, 1996].

In return for use-rights to the land, in much of China village leaders assign quotas to farming households, typically on the basis of family size, allocated land, or some combination of the two. These quotas are a vestige of the pre-reform period and entail the delivery of grain, cotton, and/or oil crops to the state at predetermined prices that can be as low as 50 percent of free-market prices [SICULAR, 1995]. With HRS, responsibility for quota delivery shifted to households. However, even after the reforms upper-level officials still hold local leaders responsible for ensuring that households fulfill quotas [ROZELLE, 1994; AND OI, 1989]. ${ }^{6}$

In absolute terms, village quotas remained fairly constant from the early 1980s until the mid 1990s. On average, quotas account for slightly less than 10 percent of village crop output. The implicit tax associated with one unit of the quota is equal to the difference between the market and quota prices for a unit of output. If we subtract non-labor input expenditures from the measure of the quota's gross cash obligation, the implicit value of the quota in 1995 was 15 percent of the village's net income from cropping.

Historically, upper-level officials required farmers to fulfill their quota in kind, however, in a growing number of villages farmers are given the option to fulfill their quota with a cash payment. Such a cash payment is equal to the difference between the market and quota prices, multiplied by the volume of the household's quota. According to our data, in the 1980s only 30 percent of all villages allowed farmers to use cash to fulfill their quotas. Within these villages, only 12 percent of households exercised this option. In contrast, by 1995, 59 percent of all villages allowed cash to be used to fulfill grain quotas. In these villages, 27 percent of households chose to use cash to fulfill their grain quota.

\section{Explanations for Reallocation Behavior}

To investigate the determinants of village reallocations, and hence tenure security, we first require a model of local government behavior. We use the canonical model of government developed by OLSON [1971], STIGLER [1971] and BECKER [1985], among others. This model assumes that the actions of a government reflect the objectives of interested parties and their respective abilities to influence the collective choice process.

Given this model, we propose three hypotheses about how local governments behave in rural China. We refer to these as the Efficiency Hypothesis, the Equity Hypothesis and the Rent-seeking Hypothesis. A test of any one of these hypotheses is, effectively, a test of the hypothesis that some influential interest group or coalition within the body politic is sufficiently interested in having the government act in a particular way. In our setting, interested parties include village leaders, households, and possibly higher-level authorities. This analytical framework is useful since it allows us to investigate the economic

\footnotetext{
${ }^{6}$ The quotas were temporarily eliminated in 1993 and then re-instated the following year. By the late 1990s, a modest subsidy rather than a tax was associated with the quotas as farmers were paid prices higher than those prevailing in the market. If China's domestic agricultural prices were to rise again, the implicit tax might reappear.
} 
factors which affect a local government's behavior and lead to secure or insecure tenure. Unfortunately, data limitations require that the actual decision-making process remain a black box. With few exceptions, we can only conjecture about the identity of individuals who provide the impetus for observed land reallocations.

\section{A. Efficiency hypothesis}

The Efficiency Hypothesis posits that land reallocations are carried out to maximize the discounted present value of agricultural profits in an environment in which farm labor and land rental markets are largely missing. In particular, administrative reallocations exploit gains from land exchange by moving land to higher valued uses. It is important to keep in mind that the Efficiency Hypothesis does not imply that administrative reallocations are as good as or better than markets at allocating land efficiently. On the contrary, our expectation is that there will typically be less unexploited gains from trade when land rental markets operate than when land exchange is conducted administratively. ${ }^{7}$ We begin by examining the a priori basis for the Efficiency Hypothesis. We then discuss tests of this hypothesis based on the relationship between village reallocation behavior and two likely precursors to inefficient land allocation: changes in household demographics and labor supply; and high levels of agricultural quota.

First, if reallocations occur for efficiency reasons, land rental markets and on-farm labor markets must operate poorly enough so that most of the gains from shifting land among households remain unexploited. As discussed above, this seems to be a reasonable assumption. Only a small fraction of China's land is being rented and an even smaller fraction of on-farm labor is being hired as late as the mid-1990s.

Second, following the models of government behavior developed by OLSON [1971], STIGLER [1971], and BECKER [1985], there must be some influential coalition within the body politic that will benefit from the increase in agricultural income that is generated when land reallocations make agriculture more efficient. This seems likely. We expect households that value land more highly to lobby for favorable reallocations. ${ }^{8}$ Moreover, local leaders may favor land reallocations for efficiency reasons. Efficiency-enhancing reallocations that increase farm profits will likely make it easier for them to collect taxes and ensure that farmers fulfill their delivery quota. Since fulfilling the village's quota obligation and promoting the growth of farm output and rural incomes are important parts of a leader's responsibilities and are linked to his bonus and promotion, a leader has an incentive to take actions to improve the efficiency of land allocation through periodic reallocations.

Finally, the Efficiency Hypothesis requires that the village-wide reallocation of land be costly. Although reallocations typically occur in the off-season, they often involve several months of administrative work. Conversations with local leaders and farmers suggest that the local leader must spend many days updating information on land use, household demographics and labor supply. Additional time is needed to discuss the new allocation schemes with farmers. Since reallocations often involve shifting more than one plot for

\footnotetext{
${ }^{7}$ Using household level data, BENJAMIN and BRANDT [2002], find that, although reallocations help to improve efficiency, the effect is marginal, and there remains significant inefficiency in the allocation of land across households within a village.

${ }^{8}$ This may occur informally, or more formally through the process of nominating and selecting likeminded village leaders.
} 
each farm household in the village, redefining and documenting plot boundaries also is time-consuming.

\section{a. Efficiency Hypothesis: Demographic and Labor Supply Changes}

At the inception of the HRS, land was usually allocated to village households on the basis of household size, possibly adjusting for the demographic composition of a household [KUNG, 1995]. In the early 1980s, few households had members working off the farm in non-agriculture and most family labor was directed to agriculture. Therefore, these "per capita" allocation rules, in addition to being easy to implement, were probably also efficient: in an economy where households can only farm, allocating land on a per capita basis would lead to a land allocation where the labor supply per unit of land, and hence the marginal productivity of land, is nearly constant across households.

After this initial allocation, increasing participation in the off-farm labor market, changes in household demographic structure, and household division gave rise to differences among households in the amount of labor that they supplied to farming. If the initial land allocations did not change, villages would experience increasing heterogeneity in household labor to land ratios, and thus rising inefficiency. Although well-developed land rental and on-farm labor markets could help eliminate these differences and ensure that the land was efficiently allocated across households, these markets are largely absent. Reallocations that move land from lower to higher valued uses can help to eliminate this inefficiency.

In the appendix, we develop a dynamic model of land reallocation to examine the optimal timing and size of reallocations. Here, we provide the basic intuition, and a set of hypotheses.

Assume initially that land and labor are perfectly matched in the village so that the marginal product of land is equalized throughout the village, and agricultural profits are maximized. Over time, differences in the marginal productivity of land emerge across farm households as a result of changes in the amount of household labor supplied to agriculture. The amount of land that must be reallocated to correct this inefficiency depends on a number of factors. The shape of the agricultural production function is important because it determines how sensitive the marginal product of labor is to changes in land holdings. The rate of change in household demographics and labor supply is also important, since the marginal product of labor depends on the amount of labor supplied. Finally, the interaction between changes in labor supply and the shape of the agricultural technology is also important: The amount of land reallocated to adjust a household's marginal product of labor depends on the product of the size of the household labor supply change, and the sensitivity of marginal product of labor to such changes.

However, even if the only motivation for reallocations is to maximize agricultural profits, as long as there are fixed costs of reallocating land, maintaining a "perfect" match between land and labor by reallocating land annually would not necessarily maximize village profits. Instead, villages would reallocate land only when the inefficiencies (and thus, potential gains) arising from the current allocation of land are large enough to offset the costs. For any given initial state of the land-labor match, the village chooses the time until the next reallocation, and the amount of land reallocated at the next reallocation. Optimal reallocation behavior maximizes the discounted present value of the present cycle's 
profits, conditional on optimizing behavior thereafter. ${ }^{9}$ Hence, if leaders are reallocating land for efficiency reasons, our first testable hypothesis is that administrative reallocations will be large and infrequent (Efficiency Hypothesis 1). As Table 1 shows, this prediction is borne out by the data.

The Efficiency Hypothesis makes other predictions as well. Along the efficient reallocation path, the time since the last reallocation or, the duration of a reallocation period will depend upon: fixed and variable costs of reallocation (Efficiency Hypothesis 2); the rate at which households' agricultural labor supplies change (Efficiency Hypothesis 3); characteristics of the agricultural technology (Efficiency Hypothesis 4); and the interaction between the rate of change of agricultural labor supply and agricultural farm technology (Efficiency Hypothesis 5). Finally, the formal analysis establishes that the amount of land reallocated at any given reallocation depends upon: All of the same factors as the duration of the reallocation period, except the fixed costs of reallocation (Efficiency Hypothesis 6); and the time since the last reallocation or the duration of the reallocation period (Efficiency Hypothesis 7).

The cost of investment foregone because of insecure tenure is an important aspect of the land reallocation process, and one that is conspicuously absent from the analysis above. To the extent that dynamic efficiency also determines land reallocation behavior, our analysis will understate the importance of efficiency as a determinant of local government behavior. Unfortunately, our data on land investment allow us to test only very basic hypotheses about the relationship between investment and reallocation behavior. ${ }^{10}$ Moreover, including investment in the formal analysis complicates notation and exposition considerably. Since we already know that tenure insecurity reduces the incentives for investment, we omit an analysis of the relationship between tenure insecurity and investment in the interests of a simpler and more transparent theoretical analysis.

\section{b. Efficiency Hypothesis: Reallocations and Quotas}

One of a village leader's primary responsibilities is ensuring tax and quota fulfillment. The relationship between quotas and reallocation has been widely discussed in the literature. KELLIHER [1997] and ROZELLE AND LI[1998] argue that leaders use their discretion over land allocation to expropriate land from villagers who do not fulfill quota obligations, and that village reallocations are driven by such expropriation.

Three facts weigh against this story. First, our data indicate that in a typical year the rate of default on quotas is probably near one percent. Given such a low rate of default it is difficult to imagine that leaders reallocate 60 percent of the land every six years as a response to non-payment of quotas. Second, if reallocation behavior is motivated by the need to punish acts of default, we expect to see reallocations occurring fairly continuously and to involve a small number of households. In fact, we observe large and infrequent reallocations. Third, in a recently completed household level survey, the authors asked 1200 households whether they had ever lost land in a reallocation as punishment for nonpayment of taxes. There were no positive responses.

\footnotetext{
${ }^{9}$ A cycle is defined to be the period between reallocations.

${ }^{10}$ In order to investigate cross-sectional differences in the dynamic costs of tenure insecurity, we require data on variables that measure the stock of investment in land at risk when tenure is insecure, or data capturing future returns to new investment in land. Variables capturing investment at risk include acreage in paddy, orchards, or terraces. Variables capturing future returns are much harder to come up with.
} 
There is, however, an alternative explanation for the role of quotas in determining land reallocation. This explanation begins with the observation that the quota is effectively a tax. To the extent that the quota is collected in-kind, there is also the potential for this tax to impose a large excess burden through its effect on farm behavior. It may distort a household's crop choice away from profit maximization. Moreover, in the presence of opportunities for off-farm labor, an in-kind quota may compel households to over-supply agricultural labor relative to the profit maximizing level.

In this situation, the Efficiency Hypothesis requires that village land reallocations be conducted to reduce the excess burden of quotas. This has two implications. First, in order to reduce the excess burden of the quota, we should see widespread willingness to accept cash payments in lieu of in-kind quota payments. Of the villages surveyed, 10 percent allowed cash payment of quotas at the inception of HRS, while 58 percent allowed cash payment of the quota in 1995.

The second implication is more subtle. In the presence of off-farm opportunities, in-kind quotas may distort a household's labor supply behavior by compelling them to supply "too much" labor to agriculture. However, this distortion will only affect those households that actually have opportunities to work off-farm. Our data suggest that well under fifty percent of households have such opportunities. This means that labor supply distortions caused by in-kind quotas can increase the gains from land exchange. Households whose agricultural labor supply is distorted by the in-kind quota should be willing to give up some of their land in order to relieve their quota obligation and free up labor for the off-farm market. ${ }^{11}$ In contrast, households whose agricultural labor supply is not distorted by the in-kind quota have a comparative advantage in producing crops to fill the quota, and should be willing to take on larger quotas in return for more land.

Therefore, all else equal, we expect that: Villages with higher quotas will reallocate more land (Efficiency Hypothesis 8); the effect of quotas on reallocation will be greater in villages with higher off-farm wages (Efficiency Hypothesis 9); and these effects will be present chiefly in those villages where quotas can only be paid in-kind. Alternatively, the "right" to pay quotas in cash should help to attenuate the effect of quotas on reallocation behavior (Efficiency Hypothesis 10).

\section{c. Efficiency hypothesis: Rental and Reallocation}

The foundation of the Efficiency Hypothesis is that administrative reallocations serve to move land to higher valued uses. While much of the analysis proceeds under the stylization that rental markets do not function at all, in fact, they operate at very low levels. It is axiomatic that such market exchange of land serves to move land from lower to higher-valued uses. Given this, if reallocations move land to higher valued use, then we should expect to see that: Rental and administrative reallocation of land are substitutes (Efficiency Hypothesis 11).

\section{B. Equity hypothesis}

Beyond efficiency, leaders may also reallocate land to increase equity within the village. In the same way that the Efficiency Hypothesis rests on the possibility that some influential

\footnotetext{
${ }^{11}$ Given the possibility of imperfections in local food markets, a household may still want to retain some of their land.
} 
coalition in the village seeks to the maximize income generated by agriculture, the Equity Hypothesis rests on the possibility that some coalition in the village has a preference for equity.

The generic success of microeconomic models taking self-interested behavior as axiomatic makes the equity hypothesis less appealing. However, the equity hypothesis is still deserving of serious consideration. First, by law, land ownership in rural China resides with the village. Villagers and leaders sometimes interpret this as meaning that every individual in the village is entitled to equal access to the land. Second, the legacy of 30 years of socialism may also have generated a preference for equity. Finally, the equity hypothesis has been prominent in the literature [e.g. BURGESS, 1997; KUNG, 1995]. These papers provide support for the notion that sufficiently influential coalitions with a preference for equity may have been successful in lobbying for equitable land reallocations.

Deriving testable implications of the Equity Hypothesis requires us to spell out more carefully what is meant by equity. Defining equity, however, is difficult since the definition of an "increase in equity" is something over which reasonable people (our villagers included) could easily disagree. Increases in equity could mean decreases in the dispersion of wage rates, income, wealth, or landholdings. To compound this problem, an "increase in equity" could also refer to decreases in the variation of opportunities to earn income or acquire wealth and land holdings. This multiplicity of definitions makes testing the equity hypothesis problematic.

Of the many possible definitions of equity, equal household per capita land holdings, with possible adjustments for demographic characteristics, has special appeal. Such rules were prominent with the introduction of the HRS in the early 1980s, while BURGESS [1997] finds that land allocations in Sichuan and Jiangsu provinces in the late 1980s continued to be consistent with such a simple demographic rule. We will call this sort of equity simple demographic rules equity, and examine the hypothesis that land reallocations serve to increase village conformance with this notion of equity.

We now state the Equity Hypothesis more formally: Costly land reallocations are conducted to minimis the discounted present value of the disutility of deviations from the land reallocation that perfectly satisfies simple demographic rules. Given this formulation, pursuing equity results in a path similar to the one implied by the profit maximizing village government. Reallocations occur only when inequality-increasing movement in household demographics grows sufficiently large that villager distaste for the inequality justifies the cost of conducting a reallocation. This implies that leaders reallocate land more frequently the greater the shifts in household demographics (Equity Hypothesis). The effect of transactions cost variables on the size and timing of reallocations under the Equity Hypothesis is analogous to their effect under the Efficiency Hypothesis.

Note that both the Equity Hypothesis and Efficiency Hypothesis 3 predict that reallocation behavior depends upon changes in household demographics, while only the Efficiency Hypothesis predicts that reallocation behavior depends upon changes in household labor supply. Therefore, a finding that reallocation behavior depends on changes in labor supply is evidence for the Efficiency Hypothesis, but not the Equity Hypothesis. However, if we find that changes in household demographics affect reallocation behavior, we have evidence for either hypothesis. Therefore, our data do not allow us to test the two hypotheses against each other. However, the data do allow us to put bounds on the relative economic importance (however measured) of the two hypotheses. The economic importance of the Equity Hypothesis is bounded below by zero and above by the entire 
effect of demographic changes on reallocation behavior. The economic importance of the Efficiency Hypothesis is bounded below by the effect of changes in labor supply behavior on reallocations, and above by the total effect of labor supply and demographic changes.

\section{Rent-seeking Behavior}

For a majority of villages the "rent" associated with the allocation of use rights to land is positive. ${ }^{12}$ Thus, village leaders may use their discretionary power to reallocate land as a way of extracting some of these rents from households. Such rent extraction could come in the form of explicit side payments or in a more intangible form (such as cooperation in other aspects of village political and economic life, e.g., a vote, effort in helping execute policy duties, etc.)

In pursuit of their own interests, village leaders could also take actions to try to limit the factors that constrain their ability to earn these rents. Specifically, since rental markets facilitate exchange among those with land and those who demand it (and thereby reduce the land rents associated with reallocations), leaders have an incentive to try to minimize the extent of rental markets. In fact, the absence of land rental markets in much of rural China is otherwise difficult to explain. It does not seem likely that the absence of land markets results from the lack of formal or informal institutions (like courts) to support exchange; many other markets, such as agricultural commodity and off-farm labor markets, flourish in the same environment. It also does not seem to be the case that there are no gains from exchange. BENJAMIN AND BRANDT [2002] find evidence that farmers within a village could gain considerably by renting land among themselves.

The failure of land markets due to the actions of self-interested leaders is broadly consistent with observation. Conversations in the field suggest that village leaders often have the authority to permit or prevent land transactions and that they occasionally exercise this authority. Researchers have documented "use it or lose it" rules under which land that is rented out risks being lost in the subsequent reallocation [ROZELLE AND LI, 1998]. Furthermore, it is a well-established fact, that to the extent that the institutional environment provides individuals with the opportunity, office holders often use the authority of their office for their own benefit. Following such logic, we therefore expect that village leaders in rural China will engage in rent-seeking behavior to the extent that such behavior is tolerated. Rent seeking by village leaders could, therefore, be partly responsible for the absence of land markets.

Our data provide the basis for two testable hypotheses that involve quota management and land reallocation. First, the correlation between the size of the quota and land reallocations (or the absence of land rental markets) may be used as a direct test of rent seeking. Arguably, village leaders are the only people in the village with a direct interest in seeing quotas fulfilled. A village leader's salary and advancement both depend upon quota fulfillment. In contrast, the quota is a tax on villagers and they would be better off if it were not collected. Since collecting agricultural quotas involves, quite literally, a collection of a share of agricultural land rents, then higher quotas should cause leaders to reallocate more land insofar as some of these rents come back to them.

\footnotetext{
${ }^{12}$ We define the rent to be revenue earned from the land minus all costs, including taxes and the opportunity cost of labor.
} 
Such a direct relationship between quotas and reallocations is also implied by Efficiency Hypothesis 8. Therefore, we cannot distinguish between the Rent-seeking and Efficiency Hypotheses by examining only the relationship between quotas and land reallocations. However, we can distinguish rent seeking from efficiency explanations for the role of quotas if we also look at the relationship between quota levels and activity in the land rental market. A leader using reallocations to collect land rents has an incentive to suppress market-based land exchanges because of the potential difficulties that third parties pose for quota liability and collection. In contrast, if reallocations are conducted to increase efficiency, then a leader should encourage efficiency-improving market transactions in the presence of quota-induced labor supply distortions. Hence, our hypothesis is that, if the impetus for reallocations comes from rent seeking leaders, then higher quotas are associated with more land reallocation and less land rental market activity (Rent-seeking Hypothesis 1).

Second, our data also provide us with an indirect way to test the rent-seeking hypothesis. For many of our villages we know whether the most recent election for village leader was contested or not. If we accept that villagers in communities that hold contested elections are better able to control rent seeking by their leaders, we expect this to be reflected in the mechanisms allocating land: In villages that elect their leaders through contested elections, there should be less administrative reallocation and more marketbased land rental transactions (Rent-seeking Hypothesis 2 ). ${ }^{13}$

\section{Description of data and variable construction}

Our data are the product of a collaborative survey effort undertaken in 215 villages in 1996 and 1997. The survey covers 8 provinces: Zhejiang, Sichuan, Shanxi, Hubei, Hunan, Hebei, Liaoning, and Yunnan. Thirty-two villages were sampled in each province, except for Yunnan (24 villages), Hebei (15) and Liaoning (16). Enumerators used pre-coded survey instruments as the basis for interviewing the village leader, party secretary and accountant in each village. The sample of villages was constructed to provide a representative cross-section of villages in each province; the eight provinces represent the major regions of China.

Our survey was designed to collect data on the emergence of major input and output markets in rural China. In particular, blocks of the survey asked village leaders for information on village land management practices, land rental market activity, household and village demographics, off-farm labor market activity, agricultural production practices, the characteristics of the village's land that may affect the difficulty of conducting land reallocations (or proxies of transaction costs), quotas, and other village characteristics. For most variables, enumerators elicited information for 1995, 1988 and the year when HRS was implemented in their villages, i.e. a year between 1980 and 1984. All variables

\footnotetext{
${ }^{13}$ While we believe that the most compelling interpretation for a negative (positive) correlation between contested elections and land reallocations (market-based land rental transactions) is that the contested election is acting as a check on rent seeking, econometric problems and the aggregate nature of our data suggest caution. The presence of competitive elections is arguably endogenous and dependent on the level of rent-seeking behavior. Also, other stories are consistent with this finding, e.g., elections may systematically bias the behavior of government in favor of households that do not prefer reallocations.
} 
used in the subsequent econometric exercises are generated from this survey. Means and standard deviations for the variables are reported in Table 8.

We first construct three measures of the village leader's land reallocation behavior, our dependent variables. The first of these, number of reallocations, is a simple count of the number of times that villages have carried out village-wide reallocations since HRS. Second, we construct a variable that is the number of years between the most recent reallocation and the previous one, duration. ${ }^{14}$ Finally, we calculate, reallocation amount, which is the percentage of total cultivated land that was reallocated during the most recent reallocation. We also compute a measure of market-based land rental transactions by dividing the total amount of land that is rented out by households by total cultivated land.

We use information on the village's population and labor market activity to obtain several measures of changes in village demographics and off-farm labor supply. To describe the construction of these variables, let $N$ be the number of households in a village, and let $l_{i}^{t}$ denote either the size of the population or off-farm labor force for household $i$ in time $t$. Then $\left(l_{1}^{t}, \ldots, l_{N}^{t}\right)$ denotes a vector describing the population or off-farm labor force of all households in a given village at time $t$ and $\left(l_{1}^{t+1}, \ldots, l_{N}^{t+1}\right)$ the corresponding quantity at time $t+1$. An intuitive index of changes in household size (labor supply) is the sum of the absolute change in household size (labor supply) in a village normalized by total village size (labor supply), or

$$
\frac{1}{\sum_{i=1}^{N} l_{i}^{t}}\left[\sum_{i=1}^{N}\left|l_{i}^{t}-l_{i}^{t+1}\right|\right] .
$$

However, we only have village-level data and so cannot construct these measures. Instead we construct a set of analogous measures using aggregate data. Since we observe $\sum_{i=1}^{N} l_{i}^{t}$, and $\sum_{i=1}^{N} l_{i}^{t+1}$, the aggregate levels of $l$ at $t$ and $t+1$, we can calculate,

$$
\frac{\left|\sum_{i=1}^{N} l_{i}^{t}-\sum_{i=1}^{N} l_{i}^{t+1}\right|}{\sum_{i=1}^{N} l_{i}^{t}}=\frac{\left|\sum_{i=1}^{N}\left(l_{i}^{t}-l_{i}^{t+1}\right)\right|}{\sum_{i=1}^{N} l_{i}^{t}} .
$$

This expression is a lower bound for 1 and we use it as a measure of the extent of household changes in population or labor supply. Annual rates of change, $r_{l}$, that correspond to 2 are constructed using the formula

$$
\left(\frac{1}{1+r_{l}}\right)^{7}=\left(1+\frac{\left|\sum_{i=1}^{N}\left(l_{i}^{88}-l_{i}^{95}\right)\right|}{\sum_{i=1}^{N} l_{i}^{88}}\right) .
$$

Using 3 we construct an index of village changes in household demographics and three indices of village changes in its off-farm labor force. In particular, the population index is the annual rate of change in the number of people officially registered as village residents. We limit the population to village residents since these are the only individuals that are entitled to consideration in the village's land allocation process. The off-farm labor index is

\footnotetext{
${ }^{14}$ For those villages that have only reallocated once, the previous reallocation would be the allocation that occurred with HRS.
} 
the annual rate of change in the total number of villagers that work off farm. We divide the individuals working off the farm into two sub-groups. The local off-farm labor index is the annual rate of change in the number of villagers that are employed locally off-farm. The migrant off-farm labor index, on the other hand, is the annual rate of change in the number of villagers that are employed off-farm and work and live most of the year outside of the village.

To control for differences across villages in agricultural technology, we utilize information on the each village's average land-labor ratio. Given a constant returns to scale agricultural technology, this ratio is identically equal to the ratio $-F_{x l} / F_{x x} .{ }^{15} \mathrm{We}$ calculate the land-labor ratio by dividing the total amount of cultivated land by the village population. We use 1988 estimates of the population and land in cultivation, values of which predate most of the reallocations that we seek to explain.

We also use our data to provide several measures of the costs of conducting administrative reallocations. The Multiple Cropping Index-MCI is the average number of crops planted per plot in a year for each village. Administrative reallocations are more likely to cause costly disruptions to farming as the number of crops per year increases. As the number of households in a village increases, so does the complexity of conducting a reallocation and so we expect transactions costs to rise with the number of households. Similarly, as the number of plots per household increases reallocations become more complex and the cost of a reallocation should rise. In contrast, the costs of carrying out reallocations should fall as the number of cadres in the village rises. We also expect that the costs of conducting a reallocation will be correlated with the number of small groups in a village. ${ }^{16}$

Since land reallocations may decrease the incentive for individuals to invest in agriculture, the disincentive should be considered as a cost of reallocation. Hence, for each village we want a variable that measures the stock of agricultural investment that may be at risk if tenure is insecure. Since paddy land requires significant ongoing investment, we use the proportion of rice paddy land as a measure of the importance of agricultural investment in each village.

Our data also include information that we can use to construct measures of the importance of the mandatory delivery quota in the village. Although officials assign quotas for grain, cotton and oil seed crops, the grain quota in most villages is by far the most important. Since we do not have complete data on the quotas for cotton and oil seed crops, we limit ourselves to grain. For each village, we know the volume of the community's grain quota in 1988 (measured in kilograms). The measure we use normalizes the quota volume by a village's 1988 total grain output. We also know for each village whether the households in a village can fulfill their quota obligation with an equivalent cash payment. Our measure, cash, is defined as the percentage of households in each village that elected cash rather than in-kind payment.

\footnotetext{
${ }^{15}$ We experimented with measures of output per unit of land, however, it was consistently out-performed by the land-labor ratio.

${ }^{16}$ Prior to the HRS, households were organized into production teams. Their current counterpart is the small group $(x i a o z u)$. These teams frequently are responsible for reallocating land among members during village reallocations. In most villages, land is fixed within these groups, though some reallocation may occur between teams. While we cannot say with any confidence whether transactions costs increase or decrease with the number of small groups, we do expect heterogeneity in administrative structures to give rise to heterogeneity in reallocation costs.
} 
For testing the Rent-seeking Hypothesis, we use data from our survey's section on village governance. We construct a contested election indicator variable that is coded one if the village's most recent election was contested and zero if not. From our interviews with village leaders, we also know if the township government rather than village leaders reserves the right to make decisions about land reallocations. We construct a dummy variable township decides that is coded one when reallocation authority resides with the township.

Finally, we have a series of other control variables. Our survey records the total number of days that labor was hired-in for agriculture in each village. We do not have information on total labor supply to agriculture, and so construct a dummy variable that simply captures if farm labor is hired-in the village in 1988. We also have estimates of per capita income for each village for 1988 and the distance to the county seat from the village (measured in kilometers). Distance should be correlated with a number of factors that may affect reallocation behavior, among them, access to off-farm employment (positively) and the ability of the county to enforce central government reallocation policies in the village (negatively). Villages located nearer to county seats may also face more pressures to convert land to non-agricultural uses, which might precipitate village-wide reallocation. Hence, it is difficult to say, a priori, which effect will predominate.

\section{Econometric model}

Our econometric inquiry is in four basic parts. First, we analyze the number of village reallocations since HRS. Since tenure security depends upon both the frequency of reallocations and their size, we then analyze the duration of the most recent reallocation cycle and the amount of land reallocated at the most recent reallocation. In doing so, we address a number of potentially important econometric issues that may bias our results. Third, we compare the determinants of market and administrative reallocations in order to provide an assessment of the potential role of leader rent-seeking in explaining the preference for administrative allocation. Finally, we examine the economic (as opposed to statistical) importance of different variables in the amount and duration regressions in order to quantify the role of equity versus efficiency considerations.

\section{Table 3 about here}

\section{A. Number of reallocations}

In any given year, we know the time since each village last reallocated its land. In principle, these data on reallocation periods in progress could generate a great deal of insight into reallocation behavior. Unfortunately these data are subject to two sampling problems: Interruption bias and length-based oversampling. ${ }^{17}$

\footnotetext{
${ }^{17}$ Interruption bias occurs because we observe interrupted reallocation periods, which are shorter than completed periods. To understand length-based over-sampling, imagine that all villages are identical, and that each draws reallocation periods from a Bernoulli density which takes the values one day or 20 years with equal probability. Despite the fact that reallocation periods of one day and twenty years are equally likely, a cross-section of periods in progress over-samples long periods.
} 
SALANT [1977] proposes a method for dealing with these two problems, however this method relies on identifying assumptions that do not hold for our data. While we cannot use Salant's method to examine our periods in progress data, we can use a simpler method that has much the same spirit. If the number of times that a village reallocates during our 15-year window provides us with information about the distribution from which villages draw hazard rates, then an attempt to explain the number of reallocations will provide some insight into the distribution of village hazard rates.

Table 3 reports the results of regressions to explain the number of village-wide reallocations since HRS as a function of changes in household demographics and labor supply, village quotas, technology, transactions costs, and village governance. All of the regressions include village income as an additional control variable. In column 1, our labor supply variable is the rate of change in total off-farm labor. In column 2, and in subsequent columns, we decompose off-farm labor into its two components, local and migrant. In order to check the robustness of these results, we conduct several related estimations. Column 3 reports the coefficients of a Probit explaining a dummy variable that is 1 if a village reallocated at least once since HRS was introduced. Column 4 reports coefficients of the corresponding OLS regression. The results of the Probit and OLS regressions are similar to the number regressions in columns 1 and 2, though levels of significance are generally lower. Column 5 presents the results of the corresponding Tobit regression, which corrects for any censoring at zero. The results of the Tobit regression are qualitatively the same as the OLS regression, but the coefficients tend to be slightly larger. Given that the Probit and OLS regressions "throw away" observed variance in the dependent variable, the following discussion focuses primarily on the number regression and the Tobit.

As predicted by Efficiency Hypothesis 3 and the Equity Hypotheses, the number of reallocations depends on the rate of change of population. Reallocation behavior is also sensitive to the rate of change of off-farm opportunities, however, the sign of this effect is opposite that of population change. We also find that villages located nearer to the county seat tend to reallocate more. One interpretation consistent with this behavior is that the variable is picking up unobserved changes in off-farm opportunities. ${ }^{18}$

To examine the role of off-farm labor further, we decompose the variable into its local and migrant components. Villages experiencing greater changes in migrant off-farm employment reallocate more times, however, villages reallocate less frequently as local off-farm opportunities change faster. Both effects are statistically significant. The opposite signs on the two off-farm labor variables are difficult to explain as a consequence of the Efficiency Hypothesis. From the point of view of a maximizing household, the only difference between the local and migrant off-farm opportunities is that labor supplied to the latter probably must be done so in much larger blocks than the other. It is not obvious why the "lumpiness" of migrant employment should be important. On the other hand, the opposite effects of the two types of off-farm labor on the frequency of reallocation may be evidence in favor of interest group politics. ${ }^{19}$ We note that the opposite signs on the two labor variables do not persist in later regressions that examine the size of reallocations.

\footnotetext{
${ }^{18} \mathrm{An}$ alternative possibility is that it is picking up returns to converting land to non-agricultural uses (which would then necessitate land reallocations).

${ }^{19}$ Villagers who work outside the village leave land behind unfarmed (or under-farmed), and are not present to lobby for their continued tenure. Consequently, high frequency of reallocation associated with high rates of out-migration may reflect pressures to redistribute to those who live in the village from those who leave.
} 
Quota levels are also positively and significantly related to the frequency of reallocations, which is consistent with both Efficiency Hypothesis 8 and Rent-seeking Hypothesis $1 .^{20}$ As the level of agricultural quota in the village increases, the number of reallocations increases. This effect is statistically significant at the five percent level. On the other hand, there are fewer reallocations in villages where decisions about reallocations are made by the township. This result, which is especially pronounced in the Probit and Tobit models, suggests that townships are helping to enforce the fifteen year tenure security provision of the HRS law, and thus restrict rent-seeking behavior.

Transactions costs also appear to play a prominent role (Efficiency Hypothesis 2). Villages reallocate fewer times as the number of plots per household and the number of households in the village rise. The intensity of cultivation as measured by the multiple cropping index, however, does not affect the number of reallocations, but does have a negative and statistically significant effect on the likelihood of reallocation since HRS. Villages reallocate more frequently as the number of "small groups" and cadres in the village increase, though the effect of the number of cadres is statistically insignificant. Finally, as the percentage of cultivated area in rice paddy in the village increases, the number of reallocations decreases. Since rice paddy land requires more ongoing investment for maintenance, this may indicate that reallocation behavior is sensitive to the importance of investment in agriculture.

Finally, we find that reallocations are more frequent as the land-labor ratio increases, and that the coefficient is statistically significant. That the agricultural technology affects reallocation behavior is an implication of Efficiency Hypothesis 4 .

In summary, the "count" regressions reported in Table 3 show that village reallocation behavior is responsive to demographic and labor supply variables, to quota levels, the costs of reallocation, and the role of townships in village land policy.

\section{B. Duration and amounts}

\section{a. Econometric issues}

In 1994 and 1995 we observe 51 of the 215 villages reallocate land. For villages that reallocate, we observe the proportion of land that changes hands and the time since the preceding reallocation. That is, we observe 51 pairs of amounts and durations $\left(S_{j}, \tau_{j}\right)>0$, and 164 villages with reallocation periods in progress for which $S=0$. We describe these data with a three equation model: 4 explains the amount reallocated; 5 explains the time since the last reallocation; and 6 explains whether or not we observe a reallocation in 1994 or 1995:

$$
\begin{aligned}
S_{j} & =A_{0} x_{j}+A_{1} \tau_{j}+\mu_{j}, \\
\tau_{j} & =B_{0} x_{j}+B_{1} z_{j}+\varepsilon_{j}, \\
I_{j} & =\left\{\begin{array}{ll}
1 & \text { if } \quad I_{j}^{*}>0 \\
0 & \text { else }
\end{array},\right. \\
I_{j}^{*} & =C_{0} x_{j}+C_{1} z_{j}+\delta_{j},
\end{aligned}
$$

\footnotetext{
${ }^{20}$ Quota interaction terms discussed earlier are not included because these variables vary within villages over the study period.
} 
where we observe $S_{j}$ and $\tau_{j}$ only if $I_{j}=1$ and $I_{j}^{*}$ is a latent variable. The third equation allows us to account for selection into the sample of villages which reallocate, but does not make use of the biased length data for periods in progress. This model provides an accurate description of the data, and since it does not use information on the length of spells in progress, avoids the intractable problem of correcting for length biased oversampling and interruption bias.

To estimate the system we must deal with three econometric problems: (1) error terms in the amount and duration equations may be correlated; (2) there may be selection bias: values of unobserved variables may differ between villages that reallocate and those that don't; and (3) the $z_{i}$ variables that occur in 5 but not in 4 may, in fact belong in 5 as well. We begin by estimating the model for a basic set of explanatory variables in order to assess the importance of these problems.

We first estimate the amount and duration equation with OLS. Provided that selection and endogeneity are not problems, these estimations generate consistent coefficient estimates. We next use predicted values of $\tau$ instead of actual values in the OLS amount regression to correct for possible correlation of $\varepsilon$ and $\mu$. Provided that $E(z \mu)=0$ and there is no selection effect, the second stage OLS regression (or TSLS) provides consistent estimates of all coefficients.

We also conduct two exercises to check if our results are influenced by selection, i.e., $E(\mu \mid I=1) \neq 0$, or, $E(\varepsilon \mid I=1) \neq 0$. First, we calculate the Heckman correction based on a Probit estimation of 6 . We then include this correction in the naive OLS regressions for duration and amount. Since all variables in the duration regression are present in the switching equation, we are able to identify parameters in the corrected duration regression only because of non-linearities in our estimate of $E(\varepsilon \mid I=1)$. Second, we test whether our results are sensitive to selection bias using the procedure described in BAKER and BENJAMIN [1997]. To conduct this sensitivity test, we first use the naive OLS regressions to impute amounts and durations to the 164 villages for which we do not observe a reallocation in 1994-1995. By scaling all of the imputed estimates by a constant, we are able to adjust implicitly the mean of the unobserved component. Reestimating the naive regression on the full sample, and using the scaled, imputed values for villages which do not reallocate, allows us to check whether our results are sensitive to selection bias. We conduct these robustness tests by scaling imputed values up and down by 15 percent. If our results are not sensitive to this sort of manipulation, then we can conclude that our results are not sensitive to selection bias, even if such a bias exists.

\section{Table 4 and 5 about here}

Tables 4 and 5 report the regression results for the Duration and Amount regressions. In column 1 of Tables 4 and 5, we report the OLS results for the basic version of the two regressions. Column 6 of Table 5 reports TSLS estimates for the amounts regression. The instruments that we use to predict years since the last reallocation are: All explanatory variables in column 1 of Table 3, plus interaction terms involving the transactions cost variables that appear in the duration, but not the amount regression. ${ }^{21}$ The coefficient on Time in the TSLS estimation is about twice as large as that obtained using OLS. This suggests that the OLS coefficient on years since the last reallocation may be biased downward.

\footnotetext{
${ }^{21}$ This instrument set passes the Hausman over-id test at the 5 percent level.
} 
However, the other parameter estimates are similar in the OLS and the TSLS. Consequently, in several auxiliary versions of the Amount regression, we only report OLS estimations.

Inclusion of the Heckman correction in the basic model generates results indistinguishable from those obtained by OLS. This test, along with results obtained using the BAKER AND BENJAMIN [1997] procedure suggest that selection bias is not important.

\section{b. Duration and Amount results}

Table 4 reports estimates of regressions explaining the duration of the most recent reallocation period. The regressions are similar in specification to the number of reallocations regressions (Table 3), although the level of significance is considerably lower for some variables. This result is not unexpected given the much smaller sample size. We find that the signs of the demographic and labor supply coefficients are unchanged, although only the rate of change of village population is statistically significant. The years since the last reallocation is also significantly shorter in villages facing higher output quotas as suggested by Rent-seeking Hypothesis 1 and Efficiency Hypothesis 8. Transactions costs also matter. The number of households in the village and the average number of plots per household remain significant, with increases in either leading to increases in the expected duration of a reallocation period. Finally, an increase in cropping intensity as captured by the $\mathrm{MCI}$ also leads to an increase in expected duration.

The remainder of this section discusses the results of a number of different specifications explaining the amount of land reallocated in the most recent reallocation.

The amount of land reallocated depends significantly on the years since the last reallocation. The OLS (TSLS) coefficient suggests that for each additional year since the last reallocation, the amount of land reallocated increases by 3\% (6\%). This is consistent with the Equity and Efficiency Hypothesis.

We find that villages experiencing more rapid change in population reallocate a larger percentage of land, which is consistent with either the Equity or Efficiency Hypothesis. Consistent with Efficiency Hypothesis 3, both kinds of off-farm opportunity variables have significant, positive effects on the percentage of land reallocated. ${ }^{22}$

The discussion of quotas in section 3 provides two potential explanations (Efficiency Hypothesis 8 and Rent-seeking Hypothesis 1) as to why the effect of quotas on reallocations should increase with the amount of the quota. We find a strong positive relation between quotas and the size of the most recent reallocation. Efficiency Hypothesis 9 also suggests that the effect of quotas on reallocation should be greater in areas where the returns to off-farm labor are greater. In column 3 of Table 5, we include an interaction term between quotas and the off-farm wage in the basic amount regression. Quotas alone become insignificant, while the interaction term is positive and highly significant. Larger reallocations are found where the excess burden of the quotas is likely to be larger.

The discussion of quota fulfillment in section 3.1 also predicts that villages will look for ways to eliminate the deadweight loss associated with binding agricultural quotas (Efficiency Hypothesis 10). One way to do this is to allow quotas to be fulfilled in cash. In column 4, we include an interaction term involving quotas and the percentage of households paying their quotas in cash. Quotas continue to have an independent effect,

\footnotetext{
${ }^{22}$ In Table 6, we aggregate off-farm opportunities into a single variable. This economizes on degrees of freedom and facilitates exposition of interaction effects.
} 
but the interaction term is negative, and highly significant. For every ten percentage point increase in the number of households paying their quota in cash, the amount of land reallocated falls by six percent. Finally, in column 5 we include both of the interaction terms involving quotas. The coefficients and the t-statistics on the interaction terms are slightly smaller than when the interaction terms are included separately, but both effects remain important. These regressions provide strong support for the role of reallocations in reducing the deadweight loss associated with quota fulfillment.

The Efficiency Hypothesis predicts that the size of the reallocation depends on the production technology as proxied by the land-labor ratio. The amount of land reallocated is positively related to the land-labor ratio: Areas with higher land-labor ratios reallocate more land. We also interact the land-labor ratio with the change in off-farm opportunities, and find that the coefficient is significant at the $1 \%$ level. The results are consistent with Efficiency Hypotheses 4 and 5.

We find that two of the transactions costs variables affect the amount of land reallocated: Amounts reallocated decrease with the average number of plots per households and the percentage of rice paddy land. Apart from the possibility that reallocating paddy land reduces investment, the well-defined perimeter of a paddy field increases the cost of sub-division relative to that on non-paddy. All other transaction costs variables affect amounts reallocated only through their effects on durations. Note that this is the prediction of Efficiency Hypothesis 6: Some transaction costs variables only affect duration while others affect duration and amount.

A central tenet of the Efficiency Hypothesis is that administrative reallocations and markets are substitutes (Efficiency Hypothesis 11). Column 2 of Table 5 includes two measures of market activity as explanatory variables in the amount regression. The percentage of land rented is highly significant and negative: A one percent increase in the amount of land rented is associated with a 1.4 percent decrease in the amount reallocated. This is consistent with market and administrative reallocations being substitute mechanisms for moving land to higher valued uses. The coefficient on a dummy variable indicating whether farm labor was hired in the village also suggests that less land is reallocated in villages in which farm labor is hired, however, the effect is not significant. The lack of precision in our ability to estimate this effect is not surprising given the crudeness with which this variable measures labor market activity.

To assess the importance of rent seeking by village leaders, we include a dummy that is coded 1 if the village experienced a contested election (more than one candidate) in the year of the reallocation, or the year before. (See column 3, Table 5 and column 1, Table 6). A contested election significantly reduced the time since the last reallocation, however, it also significantly reduced the size of the reallocation. On net, contested elections lead to more secure tenure, ${ }^{23}$ which is consistent with Rent-seeking Hypothesis 2.

\section{c. Reallocation Amounts, Rental and Rent-seeking}

Regressions for land rental reported in columns 2-5 of Table 6 for the same subset of villages as used in Table 5 help corroborate a role of leader rent-seeking behavior. These

\footnotetext{
${ }^{23} \mathrm{~A}$ contested election reduced the time between reallocations by about two years, or a reduction in the time between reallocations of thirty percent. On average, reallocations occur every six years. On the other hand, a contested election cut in half the amount of land reallocated.
} 
regressions are similar to those for the amount of land reallocated, except that the independent variable is now the amount of land rented out. ${ }^{24}$ Since we are interested in explaining differences that can be linked to differences in village characteristics, the percentage of land rented-out is a better measure of land rental. Because only 30 of the 48 villages report any rental transactions at all, we report both Tobit and OLS specifications. The transactions costs variables are omitted from the rental regressions because they are intended to reflect costs of administrative rather then rental transactions. The income variable has no explanatory power, and is dropped as well, without any effect on the remaining parameter estimates. We also allow local and non-local off-farm opportunities to have different effects.

\section{Table 6 about here}

The results of these regressions should be regarded as preliminary for two reasons. First, the sample size is quite small. Second, we expect that rental and administrative land reallocations are simultaneously determined. Enlarging our data set is infeasible, however, we could estimate a simultaneous system for rental and land reallocation. The difficulty lies in coming up with a plausible set of instruments to identify the system at the village level. Ideally, we need variables that will influence the amount of administrative reallocation, but not rental.

With these caveats in place, the results of these regressions are striking. Like administrative reallocations, the amount of rental responds positively to increases in both types of off-farm labor supply, and to the agricultural technology variables. This is consistent with our earlier finding that rental and administrative reallocations are substitutes. Note that migrant off-farm opportunities have a larger effect on land rental. One interpretation for this result is that local off-farm opportunities have a much smaller effect on household farm labor supply. Individuals working off-farm locally can still work their plots.

We also find that rental and administrative reallocations respond in opposite ways to increases in quotas and to the presence of contested elections (Rent-seeking Hypothesis 2). Where administrative reallocation increases with quotas, rental transactions decrease; moreover, where administrative reallocation decreases with contested elections, rental transactions increase. In villages with contested election, the percentage of land that was reallocated during the most recent reallocation fell by thirty percent; the percentage of land that was rented out, on the other hand, nearly doubled. This suggests that institutions that increase the ability of villagers to turn out leaders seen as being narrowly rent-seeking will increase the reliance on market land exchange. Similarly, as quotas decrease, and the amount of rent which leaders must extract from the village on behalf of the state decreases, the reliance on market land transactions is also likely to increase.

\section{d. Assessing economic significance}

Thus far we have concentrated on determining the statistical significance of relationships between reallocation behavior and various explanatory variables. Table 7 provides a basis for assessing the economic significance of these variables, and the role of efficiency versus equity considerations.

\footnotetext{
${ }^{24}$ Land rented-out is preferred to land rented-in because the latter may be influenced by land policies in neighboring villages.
} 


\section{Table 7 about here}

The first column of Table 7 indicates the percentage change in the duration of the most recent reallocation period that results from a one standard deviation change in an independent variable. This is calculated by multiplying the regression coefficients of the duration regression in column 1 of Table 4 by the standard deviation of the variable and then dividing by the mean duration of a reallocation cycle. Thus, for example, a one standard deviation change in the rate of change of population results in a 16 percent decrease in the duration of a reallocation cycle. ${ }^{25}$ The second column indicates the percentage change in the amount reallocated due to a one standard deviation change in each of the same independent variables. We find that changes in population, quotas and transactions costs have the largest effects on the duration, while changes in off-farm opportunities and village income have the most pronounced effects on the size of the reallocations.

Our estimates in column 2 of the effect of the independent variables on the amount reallocated ignore the effect of these variables on the amount reallocated that operates through their effect on the time since the last reallocation or duration. Column 3 of Table 7 incorporates this effect into our calculation. Column 3 gives the total effect of a one standard deviation change in an explanatory variable on the annual percentage of land reallocated. Quotas and income are especially important, followed by changes in off-farm opportunities, the demographic changes, and finally the transactions costs.

In summary, reallocations are most affected by the importance of quota fulfillment, followed by inefficiency in land allocation and the desire to maintain equity. Recall that the effect of changes in household demographics is attributable to both an equity and efficiency motive. High transactions cost, on the other hand, inhibit reallocation.

\section{Conclusion}

Since the introduction of the HRS in the early 1980s, much of the farm land in rural China has been reallocated by local governments. This has occurred despite government policy guaranteeing farm households the right of secure tenure for 15 years.

We consider three explanations of the land reallocation behavior of village governments. The Efficiency Hypothesis posits that local governments act to maximize the income generated by agriculture. We find support for this hypothesis on several fronts. First, land reallocation increases in villages where it is more important to reduce the excess burden associated with agricultural quotas. We also find that reallocation behavior responds to changes in household demographics, off-farm labor supply, and to interactions of the latter with variables describing the agricultural technology, tempered by the costs of carrying out reallocations. Evidence for the importance of efficiency considerations is buttressed by the fact that rental and administrative reallocation appear to be substitutes. That is, as predicted by the Efficiency Hypothesis, administrative and market reallocations both move land to higher valued uses.

The responsiveness of reallocation behavior to changes in population, while consistent with the Efficiency Hypothesis (since population and labor supply are closely linked)

25 To facilitate comparison of results on duration and amount, the change In duration due to the change in off-farm labor that we report is the sum of the individual values for off-farm migrant and non-migrant labor. 
is also consistent with an Equity Hypothesis, i.e., that reallocation behavior serves to promote equal per capita access to land. However, our empirical assessment of the relative importance of the alternative interpretations suggest that the Equity Hypothesis is probably not important economically. Even if we attribute all of the effect of population change to communal concerns for equity, our findings indicate that administrative reallocations are less sensitive to changes in this variable than to variables which reflect the importance of other motivations for reallocation.

While efficiency concerns are important, we find preliminary evidence supporting the view that reallocation is motivated by village leaders' own efforts at rent seeking. In villages with contested elections, where villagers are better able to call their leaders to account, there is less reallocation. Correspondingly, we also find that the effects of contested elections (as well as quotas) on market activity are opposite of their effect on reallocation behavior. This is consistent with the view that village leader behavior may be a source of the failure of land rental markets to develop more fully. In future work, we plan to examine the interaction between administrative land reallocation and rental using recently collected data.

In summary, our findings are broadly consistent with the view that local governments operate partially, but by no means entirely in the interests of their constituents, i.e. villagers. They also respond to interests of higher-level authorities, and their own selfinterests. As a result, our results suggest that policies that weaken the incentives for local officials to enforce quotas and which increase the integrity and prevalence of elections will contribute to more secure land tenure and increased reliance on market exchange. Since administrative reallocations leave significant gains from trade unexploited, these measures promise important welfare gains for China's rural households.

\section{Table 8 about here}

\section{Technical appendix: The Efficiency Hypothesis and changes in labor supply}

Formally, our hypothesis is that administrative land reallocations maximize the discounted present value of agricultural profits, net of costs to conduct reallocations. Over time households change their labor supply to agriculture in response to changes in their offfarm opportunities and changes in household labor endowment. Since households cannot adjust land holdings and hiring of agricultural labor is limited, agricultural land and labor gradually become "less well matched" and a village's agricultural profits decline. Reallocations correct this deterioration, but entail substantial transactions costs. As such, they occur only when the land-labor match deteriorates sufficiently to warrant the cost. ${ }^{26}$

Consider a village with one unit of farm land divided between two households. Village agricultural profit in a given year is the sum of agricultural profits in the two households. Land and labor are perfectly matched, and village agricultural profits are maximized when

\footnotetext{
${ }^{26}$ We expect reallocation behavior will affect investment behavior, and perhaps that investments in land affect tenure security. Since our data set contains very little information about household investments in agriculture, we ignore investment decisions in the formal model.
} 
the marginal productivity of land is equal for both households. For a given initial allocation of land and labor, define the quality of the land-labor match to be the amount of land that must be reallocated to achieve this optimum.

Let $F$ denote the household farming technology and let $x_{i}$, and $l_{i}$, denote land and labor for household $i$. Suppose that in Year 1 land and labor are perfectly matched, but that in Year 2 each household experiences a change in its agricultural labor supply. Since agricultural labor and land markets do not function, these labor supply changes affect the marginal productivity of land and open the door to gains from land reallocation. For a given change in labor supply, the amount of land that must be reallocated to maximize village profits depends directly on $F_{x l}$, the sensitivity of the marginal product of land to changes in labor supplies, and inversely on $F_{x x}$, the sensitivity of the marginal product of land to changes in household land allocation. From this discussion we conclude that the Efficiency Hypothesis implies that reallocation behavior depends on the technology, changes in the labor supply, and the interaction of these two quantities.

If the motivation for reallocations is to maximize agricultural profits, as long as there are fixed costs of reallocating land, it is not optimal to maintain at all times a perfect land-labor match. Instead, villages periodically reallocate land when the existing allocation is "far enough" from the optimum. In order to analyze this behavior we require a dynamic model of optimal land reallocation.

Let $\Pi^{*}$ denote the maximal agricultural profits that can be obtained in any given year and let $S$ denote the quality of the land-labor match. Since the quality of the land-labor match is defined to be the amount of land that must be reallocated to return the village to an instantaneous optimum, increases in $S$ should be associated with decreases in agricultural profits. That is,

$$
\Pi(S)=\Pi^{*}-\alpha S,
$$

where $\alpha=\left|\Pi_{S}\right|$ measures the sensitivity of profits to changes in the land-labor match. Earlier discussions suggest that this parameter will depend on characteristics of the agricultural technology. Let $v$ denote the rate at which the land-labor match deteriorates. Our earlier discussion suggests that this deterioration is closely related to changes in households' labor supply behavior. We can now write the land-labor match as a linear function of time, $S\left(t_{0}+t\right)=S\left(t_{0}\right)+v t$. Substituting into 7 we have $\Pi\left(S\left(t_{0}+t\right)\right)=$ $\Pi^{*}-\alpha\left(S\left(t_{0}\right)+v t\right)$.

This expression reflects the following intuition: village agricultural profits decrease in the time since the last reallocation and in the rate at which the land-labor match deteriorates. The rate at which the land-labor match deteriorates increases with the rate at which labor supplies to agriculture change. The sensitivity of profits to a given change in the land-labor match depends on the shape of the underlying agricultural production function.

The problem facing the village is to maximize the discounted present value of agricultural profits, which generates the following value functional:

$$
V(x)=\max _{\tau \geq 0, y \geq 0}\left\{\int_{0}^{\tau} e^{-r t}\left(\Pi^{*}-\alpha(x+v t)\right) d t-e^{-r \tau}\left(c_{f}+c_{v}(x+v \tau-y)+V(y)\right)\right\} .
$$

where $c_{f}$ is the fixed cost of conducting a land reallocation, $c_{v}$ is the marginal cost of reallocating a unit of land, $r$ is the discount rate, $\tau$ is the time between reallocations, and $t$ the time since a reallocation. 
For any given initial state of the land-labor match, $x$, the village chooses the time until the next reallocation, $\tau$, and the amount of land reallocated at the next reallocation, $(x+$ $v \tau-y)$. Optimal reallocation behavior maximizes the discounted present value of the present cycle's profits, conditional on optimizing behavior thereafter.

This statement of the problem makes the following implicit assumptions. (1) Villages never make the choice "never reallocate". While our sample contains some villages that have not reallocated, we cannot distinguish the decision "never reallocate" from the decision "reallocate less often than every 15 years". ${ }^{27}$ Given this we opt for the simpler statement of the problem. (2) Equation 8 restricts attention to discontinuous reallocation behavior. In the presence of a discrete cost of reallocation, continuous reallocation cannot be optimal if the response to reallocations is continuous. (3) Equation 8 does not consider the case when the village's initial need to reallocate land is larger than the threshold. This is a simple extension of the analysis but is not indicated by the data, which suggest that first reallocations are like subsequent reallocations. ${ }^{28}$ (4) If the leader can anticipate changes in households' labor supplies, he might choose to reallocate more land than is required to get to the optimum. Equation 8 does not allow this. This is a simplifying assumption consistent with the leader having limited ability to predict the direction of change in any given household's labor supply.

To find the value function $V$ define

$$
Y^{*}=\max _{\tau \geq 0} \frac{1}{1-e^{-r t}}\left[\int_{0}^{\tau} e^{-r t}(\Pi-\alpha(x+v t)) d t-e^{-r \tau}\left(c_{f}+c_{v}(x+v t-y)\right)\right] .
$$

That is, if we constrain all reallocation cycles to be of the same length, require each reallocation to exhaust completely gains from trade, and for the initial state of the village to be the instantaneous optimum, then $Y^{*}$ is the best we can do. Let $\tau^{*}=\tau^{*}\left(\Pi, \alpha, v, c_{f}, c_{v}, r\right)$ be the optimal time period in 9 . Given $Y^{*}$, the value function for 8 is given by:

$$
V(x)=\int_{0}^{\tau^{*}-\frac{x}{v}} e^{-r t}(\Pi-\alpha(x+v t)) d t-e^{-r\left(\tau^{*}-\frac{x}{v}\right)}\left(c_{f}+c_{v} v \tau^{*}\right)+e^{-r\left(\tau^{*}-\frac{x}{v}\right)} Y^{*},
$$

where $\alpha-r c_{v}>0$. That is, for any given starting value the optimal reallocation path involves waiting until the village needs to reallocate a certain optimal amount of land, $\tau^{*} v$, in order to return to the instantaneous optimum. When the village reaches this state, it reallocates until the instantaneous optimum is achieved.

To verify that 10 is a solution to 8 , substitute 10 into 8 . Since this expression is an identity when $y=0$, and $\tau=\tau^{*}-x / v$, it is sufficient to show that these two values are optimizing. To do this take derivatives with respect to $y$, and $\tau$. To verify that the $\tau$ derivative is zero, differentiate 9 and substitute. To verify that the constraint $y>0$ binds, follow the same procedure. This analysis follows LUCAS and STOKEY [1989, p. 123].

Differentiating 10 with respect to $\tau$ gives:

$$
-r Y^{*}+[\Pi-\alpha v \tau]-c_{v} v+r\left(c_{f}+c_{v} v \tau\right)=0 .
$$

This expression does not have an analytical solution for $\tau^{*}$, however we can differentiate implicitly. This yields two unambiguous comparative statics: $\frac{d \tau^{*}}{d \Pi}=0$, and $\frac{d \tau^{*}}{d c_{v}}>0$.

\footnotetext{
${ }^{27}$ The HRS was introduced in the early 1980's, about 15 years before our 1996-7 surveys.

${ }^{28}$ We cannot reject the hypothesis that the average amount of land changing hands in a village's first reallocation is the same as the average amount of land changing hands in subsequent reallocations.
} 
The reallocation path that maximizes the discounted present value of agricultural profits has the following characteristics. For a given initial value of the land-labor match, the planner allows the land-labor match to deteriorate until a threshold, $S=$ $v \tau^{*}\left(\Pi^{*}, \alpha, v, c_{f}, c_{v}, r\right)$, is reached and then reallocates land until $S=0$. Thereafter, the planner reallocates until $S=0$ every $\tau^{*}$ years. Hence a plot of the time path of village profits is a "sawtooth" pattern.

We note that if instantaneous profits were concave in the amount of land reallocated, e.g., $\Pi(S)=\Pi^{*}-\alpha S^{2}$, then the amount of land reallocated could depend on variable costs of reallocation, as could the upper and lower thresholds of the land-labor match. We assume that instantaneous profits are linear in the amount of land reallocated. Our data provide no basis for estimating second order terms of the instantaneous profit function. An artifact of this assumption is that variable costs of reallocating do not affect the amount of land reallocated, except by affecting the time between reallocations. ${ }^{29}$ In a more general model variable costs may impact the amount of land reallocated directly, not just through their impact on time between reallocations.

Although we cannot find an analytical solution for $\tau^{*}$, we can generate comparative statics. Unexpectedly, the time between reallocations need not be decreasing in $\alpha, v$, and $c_{v}$. Two countervailing forces are at work here. First, the "continuation payoff", i.e., the maximum present value of profits, conditional on a reallocation having just occurred, declines as $\alpha$ increases. Since $\alpha$ measures the sensitivity of agricultural profits to changes in the land-labor match, as $\alpha$ increases, the village must reallocate more often to maintain the same average profits. Consequently, either the average profits decline or expenditure on reallocations increases. In either event the continuation payoff declines. Therefore, as $\alpha$ increases, it becomes less costly to delay reallocating because the village delays a less valuable future. On the other hand, as $\alpha$ increases, the marginal benefit from reallocating at any given time increases, since the village is further from the instantaneous optimum. Hence, as $\alpha$ increases, delay is less costly and the benefit of reallocation grows more quickly. Since these two effects work in opposite directions, the net effect of a change in $\alpha$ on $\tau^{*}$ is ambiguous. Similar arguments explain why the effect of changes in $c_{v}$ and $v$ on $\tau^{*}$ are also ambiguous.

In summary, the Efficiency Hypothesis has the following implication for the behavior of the observed time between reallocations: (1) the time between reallocations depends on the rate at which household agricultural labor supplies change, the sensitivity of agricultural productivity to land-labor mismatches, and the product of these two quantities; and (2) The time between reallocations depends on the marginal and fixed costs of reallocation.

In addition, the Efficiency Hypothesis has the following implication for the behavior of the observed size of village land reallocations: (1) the size of a given reallocation increases in the time since the last reallocation; (2) the size of a given reallocation increases with the rate at which household agricultural labor supplies change; (3) the size of a given reallocation depends on the sensitivity of agricultural profits to land-labor mismatches, and the product of this sensitivity with the rate of labor supply change; (4) the size of a given reallocation depends on fixed costs only indirectly, through their impact on the timing of reallocations. In practice, this leads us to expect that some transactions costs variables will influence time and size, while others will influence only time; and (5) the size of a given reallocation depends on variable costs of reallocation.

\footnotetext{
${ }^{29}$ Barring a corner solution where the village never reallocates.
} 


\section{References}

Alston, L., G. LibecAP AND G. Bernardo [1997], “Violence and the Development of Property Rights to Land in the Brazilian Amazon", pp. 145-163 in J. DROBAK AND J. NYE (eds), The Frontiers of the New Institutional Economics, San Diego; London and Toronto: Harcourt Brace, Academic Press.

BAKER, M. AND D. BENJAMIN [1997], “The Role of the Family in Immigrants' LaborMarket Activity", American Economic Review, 87(4): 705-27.

Becker, G. [1985], "Public Policies, Pressure Groups, and Dead Weight Costs", Journal of Public Economics, 28: 329-47.

Benjamin, D. AND L. BRANDT [2002], “Property Rights, Labor Markets, and Efficiency in an Economy in Transition", Canadian Journal of Economics, 35(4): 689-716.

Boycko, M., A. Shliefer, AND, R. Vishny [1995], Privatizing Russia, Cambridge, Massachusetts: MIT Press.

Burgess, R. [1997], "Land, Welfare and Efficiency in Rural China", Working Paper, London: London School of Economics.

Kelliher, D. [1997], "The Chinese Debate over Village Elections", The China Journal, 37: 63-96.

Ho, S. [1994], Rural China in Transition: Non-agricultural Development in Rural Jiangsu, 1978-1990, New York: Oxford University Press.

KUNG, J. K. [1995], “Equal Entitlement versus Tenure Security under a Regime of Collective Property Rights", Journal of Comparative Economics, 21: 82-111.

LibecaP, G. [1979], “Government Support of Private Claims to Public Minerals: Western Mineral Rights", Business History Review, 53 (2): 66-85.

O`BRIEN, K. AND L. Li [1999], "Selective Policy Implementation in Rural China", Comparative Politics, 31(2): 167-86.

OI, J. [1989], State and Peasant in Contemporary China: The Political Economy of Village Government, Oxford, University of California Press.

Olson, M. [1971], The Logic of Collective Action: Public Goods and the Theory of Groups, 2nd ed., Cambridge, Harvard University Press.

PASTOR, R. AND Q. TAN. [2000], “The Meaning of China's Village Elections”, China Quarterly, 162: 490-512.

Putterman, L. [1993], Continuity and Change in China's Rural Development, New York: Oxford University Press.

RozelLe, S. [1994], “Decision making in China's rural economy: Linkages between village leaders and farm households", China Quarterly, 137: 99-124. 
ROzELlE, S. AND G. Li [1998], "Village Leaders and Land-Rights Formation in China," American Economic Review, 88(2): 433-38.

SALANT, S. [1977], “A Theory of Sorts”, Quarterly Journal of Economics, 91(1): 39-57.

SICUlAR, T. [1995], "Redefining State, Plan, and Market: China's Reforms in Agricultural and Commerce," China Quarterly, 144: 1020-46.

STIGLER, G. [1971], "Theories of Economic Regulation", Bell Journal of Economics and Management Science, 2: 3-21.

StOkey, N., R. LucAs, AND E. PRescot [1989], Recursive Methods in Economic Dynamics, Harvard University Press.

Whiting, S. [1996], "Contract Incentives and Market Discipline in China's Rural Industrial Sector", pp 66-110 in: J. MCMILLAN and B. NAUGHTON (eds.), Reforming Asian Socialism, The Growth of Market Institutions, Ann Arbor, University of Michigan Press.

China, National Bureau Of Statistics, [1996],"Statistical Yearbook of China", Beijing: State Statistical Bureau Publishing.

OCTOBER, 2003

Loren Brandt, Department of Economics, University of Toronto, 150 St. George Street, Toronto, Ontario M5S 3G7, brandt@chass.utoronto.ca.

Scott Rozelle, Department of Agricultural \& Resource Economics, University of California, Davis, Davis, CA 95616, rozelle@primal .ucdavis . edu.

Matthew A. Turner, Department of Economics, University of Toronto, 150 St. George Street, Toronto, Ontario M5s 3G7, mturner@chass . utoronto.ca. 